\title{
The Predictive Audit Framework
}

Siripan Kuenkaikaew. Rutgers, The State University of New Jersey. USA siripan@ pegasus.rutgers.edu

Miklos A. Vasarhelyi. Rutgers, The State University of New Jersey. USA miklosv@ rutgers.edu

\begin{abstract}
Assurance is an essential part of the business process of the modern enterprise. Auditing is a widely used assurance method made mandatory for public companies since 1934. The traditional (retroactive) audit provides after-the-fact audit reports, and is of limited value in the ever changing modern business environment because it is slow and backwards looking. Contemporary auditing and monitoring technologies could shorten the audit and assurance time frame. This paper proposes the predictive audit, a forward looking contemporary audit that will bring the assurance processes, financial and non-financial, closer to the corresponding events. Rather than merely looking backward to historical data and past errors or anomalies, a predictive audit will identify possible exceptions proactively by comparing each transaction to a normative model before that transaction is executed. The paper also discusses the possibility of performing a predictive audit in a preventive manner - a preventive audit where transactions are blocked prior to execution.
\end{abstract}

Key words: auditing, assurance, continuous auditing, predictive auditing, preventive audit.

\section{INTRODUCTION}

"Clearly the vast majority of internal auditors think that the traditional retrospective audit process adds far less value than the ability to inform the organization of risk and control trends and issues that are of importance to management" (Verver, 2012) 
Most accounting and auditing standards were set prior to the existence of current information technologies. This fact does not by itself invalidate their necessity but raises questions about their desirability, efficiency, and effectiveness. Auditing is the process of validation of the measurement provided by management to stakeholders and depends upon 1) the formality and quality of measurement rules, 2) the economics of the verification process, and 3) the purpose of the particular verification effort.

The formality and quality of measurement rules affects verifiability. Poor accounting rules that lead to vague accounting procedures allow for a wide range of allowable measures that are difficult to verify. On one hand, historical cost measures are more reliable than fair value, and, therefore, easier to verify, on the other hand the measurement relevance may counterbalance the difficulties of its verification.

The economics of the verification process determine the acceptability/framework of audit rules. Sampling procedures balanced the costs and benefits of audit verification, creating the concept of materiality which allows for "fair representation" as opposed to exact measurement. The development of faster and more effective verification processes using information technology have changed this cost/benefit equation, but the accounting and auditing standards have not yet been adapted to reflect this fact.

The purpose of the verification effort has been largely neglected in both accounting and auditing standards. The "one report for all" and the consequent "one audit standard for all" " neglect the different needs of various stakeholders like employees, investors, banks, counterparties, etc. Although the customization of financial reports for groups, organizations, or even individuals was not economically feasible in the past, it has become feasible with extant technology (Vasarhelyi, 2012).

These issues lead to the need for a reconsideration of the axioms of the audit function with implications for both the external and internal audit functions. Furthermore, companies need more than solely financial statement audits, they need assurance on a wider set of business information. Therefore, auditors should consider the need for impounding modern analytical methods and the acceleration

\footnotetext{
${ }^{1}$ The emergence of the Internal and External audit professions actually created two standards, the first much less formal than the second.
} 
and automation of business information technology. This approach of analysis with a retroactive or a predictive framework must be integrated into the assurance and auditing function.

\section{The Real Time Economy}

We are now living in a real time economy (Economist, 2002; Vasarhelyi et al., 2010b) where businesses operate continuously with less geographic boundaries, and with the need of very prompt response to key events. Timely and reliable information is vital for business decisions and competitive advantage. The traditional audit methodology cannot completely fulfill business and third party verification needs as it audits past transactions and provides substantially delayed backward looking assurance. In this setting, most of the audit procedures, particularly substantive tests, are done manually with limited sample data.

A more frequent (closer to the event, maybe continuous) audit can alleviate these problems (Vasarhelyi et al., 2010a). Continuous auditing (CA) utilizes technologies to automate audit procedures and provides speed to audit processes so that auditors may accelerate their assurance processes and creation of audit reports. The Canadian Institute of Chartered Accountants (CICA)/ the American Institute of Certified Public Accountants (AICPA) defined CA as:

"A methodology that enables independent auditors to provide written assurance on a subject matter, for which an entity's management is responsible, using a series of auditors' reports issued virtually simultaneously with, or a short period of time after, the occurrence of events underlying the subject matter." (CICA/AICPA 1999)

With the aid of advanced technology, tedious and time consuming audit work could be automated (Teeter and Brennan, 2010; Teeter, 2013). Furthermore, the extent and timing of the audit can be expanded to cover the whole population and provide more timely assurance. Management and internal auditors have to continuously monitor their business processes and internal controls to ensure efficiency and effectiveness of their operations. While CA assists with audit work and is owned by auditors, continuous monitoring (CM) aims to support management monitoring tasks and is owned by management. Littley and Costello 
(2009) argue that management performs CM while internal audit focuses on CA, two complementary functions. CM is defined as: "A feedback mechanism used by management to ensure that controls operate as designed and transactions are processed as prescribed. This monitoring method is the responsibility of management and can form an important component of the internal control structure" (KPMG, 2010). Management uses CM to monitor compliance with, and exceptions involving, transactions. Monitoring results can be used to support day-to-day or higher level management decisions as well as to improve performance and integrity of processes and controls. CA lets internal auditors actively investigate internal control exceptions as soon as they occur. The exceptional transactions might typically be held for investigation before being released for further processing. Also, CA will reduce errors, anomalies, and/or fraud within the business processes.

CA allows for the emergence of the predictive audit, the next generation of audit methods that use together both backward looking and predictive methods. The predictive audit uses analytical methods to predict the expected future outcome of process performance at the transaction, intermediate, and aggregate levels.

The idea of the predictive audit is that instead of only looking backward to audit the past events and create adjustments based on changes or errors that have already occurred, auditors can perform the audit in a way that they could rapidly detect (predictive) or prevent (preventive) irregularities and anomalies or create adjustments in an ex-ante manner.

Based on analytic methods, the predictive audit can predict the possible outcomes of a process from operational parameters. Auditors and management can use this information for auditing and/or management purposes. For example, fraudulent service cancelations can be predicted to detect employees who violate corporate policies (Kuenkaikaew and Vasarhelyi, 2013). More importantly, external auditors can predict final audit results based upon quarterly and/or monthly data, and, thus do not have to wait to perform all the year-end data verification processes prior to issuing an opinion.

The remainder of the paper is organized as follows: Section 2 provides a discussion of audit automation. Section 3 presents the predictive audit framework. 
Section 4 discusses methodological issues. Section 5 presents a case study of a predictive audit implementation, and Section 6 offers concluding comments.

\section{PROGRESSIVE AUDIT AUTOMATION}

Enterprise resource planning (ERP) software has become a common platform for many businesses in all ranges from manufacturing to service. With many system configurations, numerous user settings, and an excessive volume of transactions continuously processed through each system, it is generally infeasible for auditors to manually audit ERP systems. CA and CM are methodologies to address this difficulty. To adopt CA/CM, companies have to be well prepared and organized, able to incorporate new technologies, and able to adjust their processes to support $\mathrm{CA} / \mathrm{CM}$. Most extant audit automation is progressive rather than comprehensive. In this progressive audit automation domain, the actual audit processes are modularly formalized. As such, these processes are broken down into small steps or subcomponents and automated where possible.

Alles et al. (2006) experimented with audit automation concepts in the pilot implementation at Siemens, stating "The pilot implementation confirmed the Vasarhelyi et al. (2004) hypothesis that CA would first automate existing audit procedures rather than reengineer them to better suit the needs of the CA system". In the pilot project, the research team classified audit programs into two groups, audit programs that are automatable and those that require reengineering. Ultimately, the internal audit management team believed that the automated audit programs facilitated cost savings and increased efficiency of the internal audit department.

Teeter and Brennan (2010) extended the pilot implementation project of Alles et al. (2006). They experimented with automating the audit programs of a newly acquired division of the company, and created a universal rule set that could be used as a standard for other divisions. While evaluating the existing audit programs, they found that some types of control tests are easier to automate than others, and these are typically targeted for initial automation. The researchers considered these controls easy targets of implementation - "Easily automatable controls tests were identified as "low-hanging fruit" because they didn't require 
intense work to automate. These tests included authorization, configuration, separation of duties and use-as-is (UAI) tests." (Teeter and Brennan, 2010)

The challenges of the automation process in this study consisted of three major issues. The first issue pertained to prioritizing rules that are relevant to company operations. The second issue related to incompatible programs or bugs in the current software platform. The last issue dealt with the proper functioning of basic controls. Eventually, the researchers concluded that 63 percent of the audit actions could be automated such that alarms could be set to notify management in the event of control violations. Consequently, a continuous control monitoring rule book was created as a set of standards and guidelines for conducting an internal IT audit. Thus, the audit process can be shifted from testing transactions to testing the rules themselves. The result of automation can be a reduction in time and travel expenses for the audit, as auditors could remotely review automated controls.

Audit re-engineering is a systematic review and alteration of audit processes, where possible, to be in alignment with the flow of data in a company and improve audit procedures. An organization may decide to reengineer audit processes to improve audit efficiency (Alles et al. 2006). Warren et al. (2012) formalized the audit process and re-engineered its structure for the order-to-cash audit processes of a consumer business firm. Specifically, they focused on the elimination of redundant processes and inefficient attributes in that audit cycle. Initially, formalized rules and audit questions were generated. Those rules and questions were then converted into queries, dashboards, and analytic procedures. Available data was assessed, and audit procedures were reengineered according to data behavior and characteristics. Some of the criteria that were used to evaluate data in Warren et al. (2012) included "...how data is generated (manual vs. automated), when and at what intervals data is updated (discrete vs. continuous), and where the data is located (local vs. remote)." As a result, audit procedures were more in line with available business data. In addition, audit timing and location were revised according to the findings. In conclusion, the researchers found that audit reengineering could improve audit efficiency, and allowed auditors and managers to focus more on business risks.

A company, in the US SEC jurisdiction or a conglomerate, has to comply with a number of laws and regulations. Examples of such legislation include the 
Sarbanes-Oxley Act, Foreign Corrupt Practices Act (FCPA), USA Patriot Act, and other industry specific regulations (KPMG, 2010). Given this situation, a company must consume significant resources in fulfilling the requirements of such legislation. Fortunately, there is an opportunity for firms to substantially automate compliance with existing and new regulatory requirements in an effort to better address the associated compliance burden. Compared with manual audits, automated audits (Alles et al., 2013) could substantially improve the monitoring of regulatory compliance, which is very detailed and should be continuously monitored.

\section{Predictive Auditing}

Continuous auditing aims to satisfy real time business needs. A voluminous amount of CA literature has been evolving, and a number of companies have started to adopt some type of continuous audit. Also, these organizations are trying to improve and expand the application of CA in their companies (PricewaterhouseCoopers, 2006; Brown et al., 2007, Vasarhelyi et al., 2012a). Using CA technology, a number of audit tasks can be automated and efficiently performed. Therefore, auditors can focus more on business risks and could continuously or frequently, rather than periodically, act on the entire transaction population instead of a mere sampling of transactions. This allows auditors to detect errors on a timelier basis, and simultaneously increases audit effectiveness. While companies implement CA for assurance purposes, it is implied that the monitoring of processes and transactions will also be incorporated in the system. If this monitoring is also used for management purposes, it is defined as CM. Even though it is not necessary for a company to implement both CA and CM, they are complementary mechanisms. Companies may deploy both processes to maximize the usage of resources and benefit from resulting synergies. To implement CM, management can preliminarily select existing CA techniques that are suited to a firm's operational processes and adopt them as CM (Vasarhelyi et al. 2004, Littley and Costello, 2009). Likewise, auditors can take advantage of existing controls in $\mathrm{CM}$, and utilize them to support their CA initiatives (Vasarhelyi and Alles, 2005). Technology plays an important role in contemporary and future auditing. Audit automation (Teeter, 2013) can be performed by automating the traditional audit (progressive audit). The audit 
automation also greatly facilitates the development of forward looking audit techniques that can be used either as a measurement benchmark for close to the event auditing (predictive audit) or, in certain cases, as a way to avoid likely defective transactions from being executed (preventive audit) .

Figure 1 depicts contemporary auditing. The traditional audit is still needed and will be a foundation of the predictive audit. This predictive audit is an approach for performing CA that applies a prediction methodology to the audit. The progressive audit is applicable to existing audit procedures, and entails a backward looking audit, while the predictive and preventive audits are forward looking and focus on upcoming events. Results of the predictive audit (not preventive) could be used to identify a process or set of processes that have a high probability of irregularities or errors. Later, when these results are found to be robust, they can be used to construct additional rules or filters, and implemented as preventive controls (the preventive audit) in those processes.

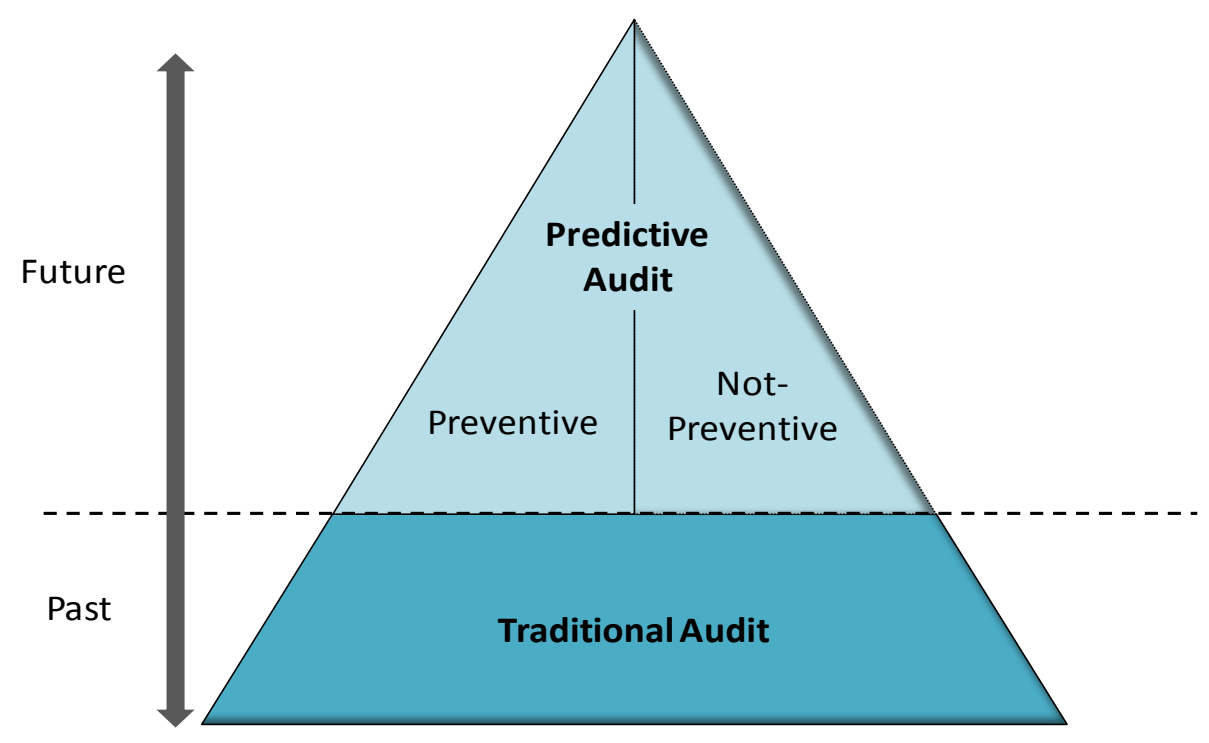

Figure 1: Contemporary Auditing

\section{Contemporary Audit}

In the coming age of close to real time auditing and control, auditors and management not only want to verify past activities, but they also want to predict future events for improved control and faulty transaction prevention purposes. The predictive audit is an emerging concept that could fulfill this vision. 
Specifically, the predictive audit is a forward looking approach that examines the validity of transactions before they are executed by comparing actual activity to timely normative models. Based upon such analyses, auditors and management are able to be notified beforehand about any problematic transactions and/or processes. Then, individuals may investigate and resolve these issues prior to conducting any associated recording activities. Consequently, the predictive audit may turn an audit towards the future by taking a proactive stance in conducting audit activities. Based upon this, audit paradigms will change from the backward, periodic audit to the forward, continuous audit, and from a detective to, when possible, preventive stance.

The predictive audit could strengthen the control environment of a company and create better feedback mechanisms for management. In particular, auditors or management could examine errors and/or irregularities that cause transactions to be flagged, or monitor transactions to ensure that, whenever problems occur, resolutions could be promptly implemented. Flagged transactions could be examined to determine if they are allowable. If not allowable, they could be subjected to further investigation. In addition, companies could consistently refine preventive controls by establishing additional checkpoints to improve business process rules. Accountants who are responsible for period-close adjustments could use the predictive audit findings to create and enter preventive adjustments. For example, by comparing results from predictive models with operational budgets, auditors and accountants could identify possible variances that may occur, and make plans to address them.

There are several differences between the predictive audit and the traditional audit. These differences relate to control approach, objectives, audit area, frequency, measurement, and method. For convenience, Table 1 compares different perspectives between the traditional and predictive audits in greater detail. Data that is to be used in a predictive model has to preferably be in an electronic format. Therefore, hard copy data must be digitized prior to inclusion. In addition, audit procedures should be automated where possible to gain the most benefit from this new audit paradigm. Similar to other CA projects, an initial implementation/conversion will require considerable investment in technology, human resources, and management support (Vasarhelyi et al., 2012b). Even 
though it entails substantive effort in the beginning, in the long run, it is expected that the benefits will justify these costs.

\begin{tabular}{|c|c|c|}
\hline Area\Audit & Traditional Audit & Predictive Audit \\
\hline $\begin{array}{l}\text { Control } \\
\text { Approach }\end{array}$ & Detective (Backward) & Preventive (Forward) \\
\hline Objective & $\begin{array}{l}\text { Support audit opinion on } \\
\text { financial statements }\end{array}$ & $\begin{array}{l}\text { Support not only for financial purposes; include } \\
\text { but not limited to operational audit, compliance, } \\
\text { and control monitoring }\end{array}$ \\
\hline Audit area & $\begin{array}{l}\text { Financial statements at an } \\
\text { account balance level }\end{array}$ & $\begin{array}{l}\text { High risk areas in financial statements and } \\
\text { operation processes at transaction, sub-account, } \\
\text { and account levels }\end{array}$ \\
\hline Frequency & Periodic & Continuous or close to the event or frequent \\
\hline Measurement & Static & Dynamic \\
\hline Method & $\begin{array}{l}\text { Manual } \\
-\quad \text { Manual } \\
\text { confirmations } \\
-\quad \text { Document vouching } \\
\text { by sampling } \\
\text { - Inventory counts } \\
\text { Use statistics and/or ratios }\end{array}$ & \begin{tabular}{ll}
\multicolumn{2}{l}{ Automated } \\
- & Automatic confirmations \\
- & Data analysis of entire population \\
- & RFID, barcode \\
Use data analysis and/or data mining techniques
\end{tabular} \\
\hline
\end{tabular}

Table 1: Predictive Audit Characteristics

\section{Types of Prediction}

The predictive audit associates past and exogenous data as well as knowledge of the processes to predict risks, control trends, level and flows, and other parameters of the business process. These predications are compared with the actuals revealed by management for monitoring and assurance purposes. Where discrepancies of substance arise, alerts are generated (predictive audit not preventive) and potentially blocked (preventive) execution.

\section{Risks}

Moon (2013) divides risks to be monitored in the Continuous Risk Monitoring and Assessment (CRMA) methodology into three major categories: 1) operational, 2) environmental and 3) black swans. These risks are monitored, and, when substantive changes are observed, analytical methods are used to rebalance audit procedures and potentially refine management actions aimed at improving the balance of audit procedures being applied. The prediction of risk changes would allow CRMA to improve situations in a proactive manner. 


\section{Control trends}

Controls are evaluated in the post Sarbanes-Oxley world, and their quality is reflected in the quality of auditee data. The structure, current trends in the evaluation, and frequency of data alerts provided by control systems serve as predictors of future trends in controls evaluation. While the measurements of control effectiveness proposed in the literature (Debreceny, 2006; Doyle et al., 2007; Ashbaugh-Skaife et al., 2009) are still coarse, they may serve as predictive measures of irregularities as well as proxies for management quality.

\section{Levels and flows}

The traditional audit aims to assure the reliability of measurements presented by management concerning data levels (Balance Sheet) and flows (Income Statement and Funds Flow). Their prediction allows for the creation of a more competent benchmark for continuous monitoring and continuous auditing relative to the more traditional "standards" used by Vasarhelyi and Halper (1991). For example, a company could predict a level of sales returns before the year end using historical information related to sales and returns in previous periods, and could create adjustments in advance or monitor for irregular returns.

\section{PREDICTIVE AUDIT: THE FRAMEWORK}

\section{Forward Audit}

Auditors review past transactions to support their opinion on financial statements, and investigate past events to ensure that controls were obeyed, and no significant exceptions occurred. Auditors periodically review business transactions. Some processes will be audited monthly, quarterly, annually, or even every other year (Vasarhelyi et al., 2010a). Although traditional audits have retroactive value, this backward looking audit creates a time lag between event occurrence and the time of associated assurance that influences the decision making of stakeholders.

In the current auditing paradigm, any errors or irregularities that occur may not be uncovered in a timely manner and this may be detrimental. Conversely, continuous auditing and continuous control monitoring allow for immediate response to the ever changing business environment. Using these methods, 
management and auditors may explore emerging problems soon after the event, and, thus, optimize the likelihood of recovering from errors and/or irregularities.

In a competitive business environment, the value of a company is its future economic performance. From an auditing and control perspective, if auditors could identify processes that have a high probability of producing irregularities, or controls that deviate from benchmarks, they could use this information to prepare for audit planning and consequent procedures. The predictive audit utilizes historical and/or current data to predict potential future outcomes. Predictive models can identify patterns, trends, and/or benchmarks, and predict processes or transactions that may deviate from predefined controls. As such, auditors can plan ahead for the audit, and scarce resources such as time and personnel can be allocated more efficiently. If anomalies are detected, auditors may examine source transactions to intervene and/or prevent possible adverse consequences. Also, management can use a predictive model to identify high risk areas that will need greater attention. Moving forward, management can then apply more preventive controls or filters to processes in those areas.

\section{Beyond the financial purpose}

As stated earlier, the primary objective of the traditional audit is to assess and validate financial statements in an effort to provide reasonable assurance that they are free of material misstatement. Audit work focuses on testing and verification of the accuracy of account values and balances. By comparison, the objective of continuous auditing is "to provide assurance on both financial and non-financial data at a more detailed level and on a much wider set of data" (Vasarhelyi et al., 2004). In addition to supporting the requirements of the financial audit, the predictive audit can be applied to non-financial audit tasks such as operational auditing, compliance testing, and controls monitoring. Furthermore, it can be applied to areas such as customer relationship management, supply chain, and manufacturing.

The implementations of ERP systems and relational databases in many organizations facilitate the automation and electronization of processes and data (Vasarhelyi and Greenstein, 2003). In these systems, the controls are shifted from the account level to the transaction level such that "The proliferation of business processes and the ubiquity of technology and automation will...change the minimum level of control from accounts (embodying multiple transactions) to 
individual transactions...." (Vasarhelyi, 2011). The predictive audit can identify possible exceptions at both aggregated and disaggregated levels, depending upon input data. As such, it can be applied to account balances or to individual transactions. As predictive audits require significant investments in technology and automation as well as concentration in data analytics, companies may only consider the application in high risk areas of accounting systems and operational processes to be cost-effective (Chan and Vasarhelyi, 2011).

\section{Continuous measurement}

Businesses need measurements to track their performance in various dimensions. They need not only financial measurements, but also non-financial measures. Financial statements are used to identify the financial status of a business, and accounting is the method for measuring that status. As the nature of business has evolved, measurements have been adapted to continue to effectively evaluate and reflect the actual status of the business. For example, in the digital era, companies' assets are not only tangible, but also include intangibles such as intellectual property, human resources, and digital assets. Given this fact, one question for accountants and auditors is how to measure the value of these intangible assets (Vasarhelyi and Greenstein, 2003). Existing tangible asset measurement schemes such as LIFO and FIFO inventory methods would not be appropriate for intangible assets.

A company can select many measures, either financial or non-financial, that are applicable to its strategic goals, and define expected levels of accomplishment which will be used as a guideline for employees. Well-known and widely used non-financial measurements include the balanced scorecard (Kaplan and Norton, 1992) and key performance indicators (KPIs) (Venkatraman and Ramanujam, 1986; Ahmed and Dhafr, 2002; del-Rey-Chamorro et al., 2003). A balanced scorecard as defined by Kaplan and Norton (1992) is a measurement schema that includes one financial measure and three operational measures including customer satisfaction, internal processes, and organizational innovation and improvement activities. The balanced scorecard allows management to simultaneously monitor an organization's performance in various views. A key performance indicator (KPI) is "a number or value which can be compared against an internal target, or 
an external target benchmarking to give an indication of performance. That value can relate to data collected or calculated from any process or activity" (Ahmed and Dhafr, 2002).

Real time audits are needed, but not viable using manual methods and static measures. Vasarhelyi and Alles (2005) state "A dynamic world cannot be well measured with static measurements, and technology exists for a more dynamic method of measurement to evolve." Auditors are not required to provide assurances in real-time, but the usage of ex-post facto data is of limited value. CA decreases the time lag of assurance and allows auditors to provide an opinion in a more timely fashion, if not on an evergreen basis (CIA/AICPA, 1999). A continuous measurement system implemented in multiple business cycles simultaneously is needed to measure vibrant business processes. The predictive audit applies continuous measurements to business processes by measuring variables and applying analytic models. Measurements in the predictive audit can consist of both financial and non-financial metrics that truly reflect operating processes and audit objectives. For example, a measurement can be an inventory turnover ratio from financial statements, or the number of defective products derived from KPIs.

\section{Role of automation in the predictive audit}

Many traditional audit tasks are completed manually because some of the accounting documentation exists in paper form. This manual work is laborious and time consuming. In the contemporary audit, many of these tasks can be automated. Advanced technologies, cheap storage, sophisticated devices, and ERP systems facilitate the automation of audit procedures. In this context, auditors can automatically collect data by downloading directly from a company's ERP system or an audit data warehouse. Then, various audit-aid tools and techniques can be used to analyze the data. Many organizations utilize automated tools for automatic sensing, such as radio frequency identification (RFID) chips and barcode readers in an inventory tracking system that send information to an ERP system. These technologies both facilitate automation and make implementation of CA more cost-effective (Vasarhelyi and Kogan, 1999). In addition, they substantially reduce latencies between events and associated data capture.

For all business and assurance processes, four types of latencies can be defined: intra-process latency, inter-process latency, decision latency, and outcome latency 
(Vasarhelyi et al., 2010a). A latency in an audit process may be reduced by electronizing (Vasarhelyi and Greenstein, 2003) audit activities such as using electronic working papers, electronic communications, decision support systems, and real time feeds of evidence (Teeter et al., 2010). Figure 2 shows the audit process latencies, and possible solutions via electronizing audit activities. The predictive audit could fully benefit from automation in several respects. First, automated systems reduce errors and time lags resulting from manual processes. Also, data in an automated system tend to have fewer errors than that residing in a manual context. Second, with electronization solutions, as soon as data are entered into a system, they may be automatically fed to a predictive model. The model, then, could immediately process and provide notification relative to exceptions.

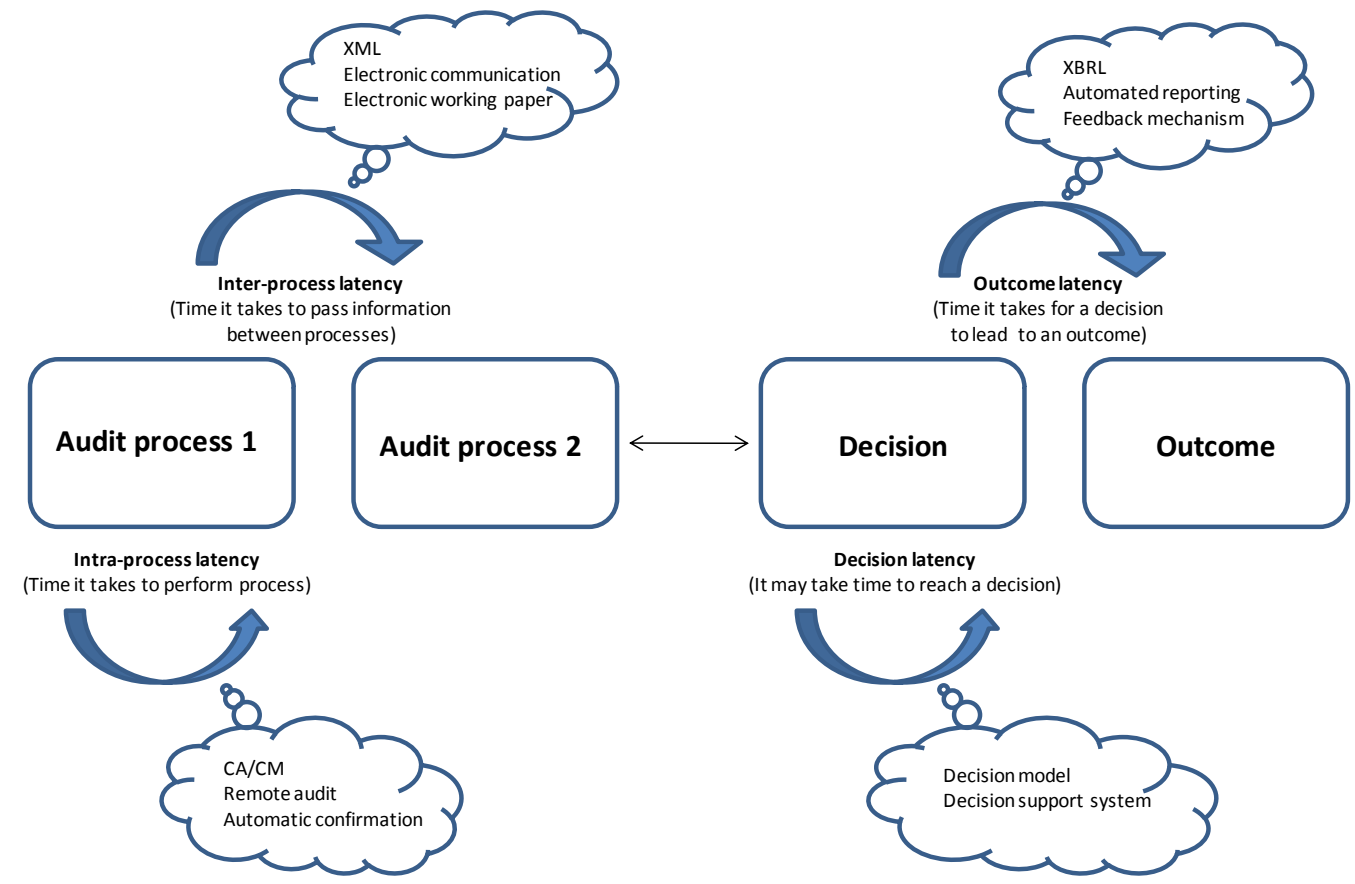

Figure 2: Audit Process Latency and Electronization (Adapted from Teeter et al., 2010)

\section{Prevention}

Forensic work often entails the usage of advanced analytics relying on historical data to screen transactions that may be faulty (Kim, 2011). These transactions are typically chosen because of specific characteristics and may be 
given discriminant scores based on the level of potential fault. The larger transactions and holders of more suspicious scores are typically examined manually. The predictive audit uses similar advanced analytics to predict levels and flows or parameters of transactions. The lack of confidence level for the transaction is the result of a discriminant function. If discriminant functions can be derived and are reliable for screening past transactions, they also can be used to determine the reasonableness of future transactions. When problems emerge, the following question might arise:

why allow a transaction to be executed if it has a high probability of being faulty?

In fact, the predictive audit can use the weights in discriminant functions to prevent the processing of suspect transactions (Alfuraih et al., 2002; Cornish and Clarke, 2003; Sisalem et al., 2006). In this manner, the preventive audit applies a forensic model to create filters to prevent anomalous transactions from being posted. Filtering rules are placed in the process, and can flag transactions with a high potential for exceptions, thus prompting further review (Figure 3). This methodology enhances the audit by exception method, especially in internal audit, and could be designed to have an interface to connect with the CM system for management purposes.

Kim (2011) incorporates a forensic analysis routine into $\mathrm{CA} / \mathrm{CM}$ to create an anomaly detection model for the wire transfer process of a bank. The model deploys an unsupervised method with a series of indicators to create a suspicion score. This score is assigned to each wire transfer payment transaction that passes through the model. The transactions with scores that are higher than an established threshold are labeled as potential anomalies and are forwarded to internal auditors for investigation. The filtering model is placed at the beginning of the process for early detection of possible exceptions, thus preventing them from further processing. The model screens data for patterns or faults under different scenarios. If exceptions are found, they are flagged and included in the exception report. Auditors then examine those errors on an interactive basis. Moving forward, the results of investigations are used to refine the model. As an example, Li et al. (2013) uses the Dempster-Shafer model in multiple interactions to fine tune a model. 
Although it would be desirable if preventive models existed in all circumstances, as this would substantially improve the quality of data, many potential factors make this infeasible including: lack of reliable forensic models, largely manual processes, substantial level of investment needed for development, lack of tailoring of filters, etc. The predictive audit can be categorized as either a predictive audit with prevention (preventive audit) or a predictive audit without prevention. The key difference is that, in a preventive approach, transactions are potentially not executed if found to have a high threshold of risk and submitted to a special audit review group that subsequently deals with the transactions. This places auditors in an operational mode, and raises questions of independence from the traditional point of view. Elder-de-Aquino et al. (2013) implemented 18 filters to monitor bank branches relative to overnight transaction processing. The audit monitoring group reviewed these transactions, and, when applicable, escalated them for review by higher management. Also, this process was performed in an ex-post-facto mode. If these transactions had been reviewed and vetted ex-ante, a "preventive audit" would have effectively been performed. From a traditional conceptual view, this may have been seen as a meta-control function and not considered auditing. With a discussion of key components in the predictive audit framework completed, the next section proposes ten steps for the creation of an actual predictive/preventive audit system.

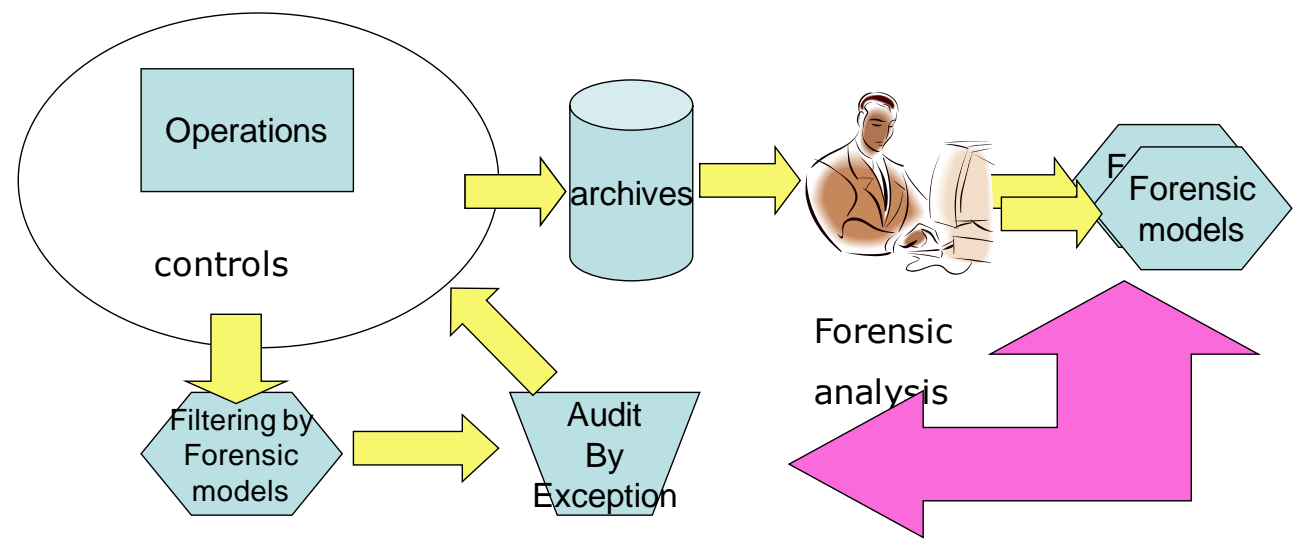

Figure 3: Incorporating Forensics into the CA/CM Philosophy 


\section{Predictive Modeling}

Auditors have long been using analytical methods to identify relationships between sets of data (Tabor and Willis, 1985; Hirst and Koonce, 1996; Chen and Leitch, 1999; Cohen et al., 2000; Glover et al., 2000; Church et al., 2001; Green and Trotman, 2003; O'Donnell and Schultz, 2003). Analytical review usually applies to account balances in financial statements. Using this method, auditors could find trends, fluctuations, or irregularities that happened over time. In the past, auditors could analyze data only at the aggregate level because of limitations in data availability, resources, and technology. Furthermore, much of the audit work had to be performed manually. Data was scarce, and audit staffing and timing was limited. Fortunately, current tools and technology allow much audit work to be automated, which changes the timing and extent of audit tasks. Due to substantial improvements in technology, data storage has become cheaper and has far greater capacity relative to the past, such that companies can tolerate the proliferation of data. In addition, auditors, both internal and external, have more access to data, and are able to perform analyses at disaggregated levels and in expanded detail, especially via application of continuous auditing methods.

Using appropriate data analysis techniques, a predictive audit model can be constructed. In addition to computing basic statistics and ratio analyses that are widely used in a traditional audit practice, the predictive audit uses sophisticated methods such as data mining and machine learning techniques to gain more insight into data analytics at a detailed level. Also, trends and irregularities can be predicted, and results of predictive models could direct auditors' attention to suspicious items. A predictive model formation is illustrated in Figure 4.

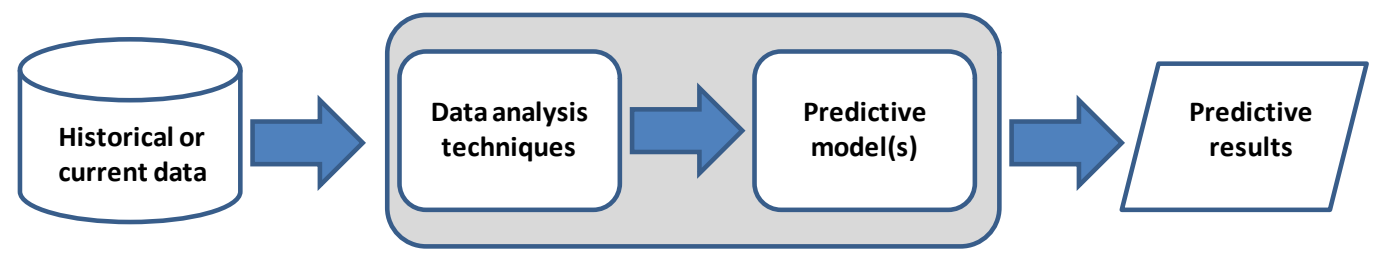

Figure 4: Predictive Model Formation 


\section{Steps in the creation of a predictive/preventive audit model}

The steps in the continuous forensic and preventive audit process are:

1. Decide on a profile of risk

Each company has different risks. Some of them depend on the type of business and are known as inherent risks. Other risks are largely due to factors such as state of the economy, competitors, and regulations. Management has to identify the types of risks it faces, potential impacts of those risks, tolerance level for risk, and possible palliative measures for these risks. When a risk profile is chosen, it can be used in many contexts such as to identify critical business processes, or determine operational processes that have a high propensity of risk and need close monitoring. In addition, a risk profile can also be used as a guideline for development of KPIs or a baseline in a forensic model. For example, an insurance business has high risks regarding customer claims. Specifically, the legitimacy of these claims is often in question. As a palliative measure, the company will invest in the claim verification process to reduce the risk of approving false claims.

2. Identify and understand the system

Management needs to identify business processes and systems for which they want to implement the preventive audit. A clear scope of the target systems will ease a project team's work. The project team must understand the system's structure and features, as each system has different characteristics. The more understanding there is about the system, the more successful the project will be.

3. Capture and clean relevant data

One of the key processes in data analysis is to capture relevant data. A company may have a large amount of data, but not all is relevant to the target analysis. After data is extracted, it needs to be scrubbed because it may not be in a format suitable for analysis. In particular, there may be errors such as missing data, duplicate data, wrong data types (e.g. text in a numeric field, numeric data in a date field, etc.). Also, the data may have 
an unreasonable range or order. For instance, in an employee database, an employee may have a birth date after a hire date. All these errors have to be cleaned before that data can be used in analyses. Otherwise, results may be unreliable.

\section{Create KPI and extraction models}

After data has been prepared for analysis, a forensic model can be created using several techniques such as descriptive statistics or sophisticated analytical methods. A complex method is not necessarily better than a simple one. Often, a complex model requires too many resources and effort so that it is less useful than anticipated. Usually, a model is based on characteristics or behavior of a target business process. Thus, the understanding of data and business routines is very important.

Each result from the model must be compared to a predefined baseline. Therefore, the company needs to define a baseline or benchmark for each measurement. This baseline can be generated from existing KPIs or newly established criteria with acceptable or expected levels. If the analysis result deviates from the baseline, it may be a signal of an anomaly. For example, if a KPI indicates that money transfers should be cleared within one business day, clearing transactions that take more than one business day may need further investigation.

5. Run models under different scenarios

Different processes or activities can cause various types of errors and irregularities. In some instances, similar errors may originate from different sources. Although it is difficult to identify all possible business scenarios that may cause problems, especially in terms of irregularity or fraud, it is desirable to create business cases that cover as many circumstances as feasible. Additionally, in different scenarios, the model may behave differently. Thus, the model has to be run under various conditions to ensure that it is robust and working as expected. For example, in the case of a loan, a customer may pay equal installments each month until the end of the contract, or he/she may make a balloon payment before the contract matures. While building the model, these two scenarios 
must be included, and the model has to be tested using these differing conditions to ensure that it works properly for both cases.

6. Place filters at the beginning of processes

The purpose of forensic models in the preventive audit is to prevent undesired anomalies in the system. Instead of placing the model at the middle or at end of processes, it will be placed at the very beginning of the processes in order to screen potential anomalies as soon as possible and prevent them from execution or passing through to the next process. An example that happens routinely is when a customer buys a product via credit card. In this case, the seller first needs the transaction to be authorized by the credit card company before the seller can process the payment and issue the corresponding transaction receipt. If the credit card has a problem, the credit card sale will not be processed.

7. Examine interactively and audit by exception

Any transaction that exceeds a predefined threshold is flagged and sent to internal auditors for further investigation. The system can generate an alarm in real time. Therefore, internal auditors can examine exceptions found on an interactive basis. The preventive audit helps create an audit by exception mechanism within an internal audit organization. Consequently, internal auditors can pay more attention to the transactions that are identified as exceptions by the system.

8. Create interfaces to continuous monitoring

A company can create a link between an internal audit system and management's continuous monitoring system. This fully integrated system will allow management to monitor activity, and examine any exceptions so that it can respond to potential problems in a timely fashion.

9. Continue the forensic model development process based on filtering results

A preventive audit model filters transactions and generates real time results, which allows either internal auditors or management to investigate exceptions on an interactive basis. To enhance the efficiency and 
effectiveness of the preventive audit system, the results of exception investigations can be used to improve and update the forensic model.

10. Rely, as an external auditor, on internal audit work

Statement on Auditing Standard $65^{2}$ allows an external auditor to rely on internal auditors' work to a certain degree if that work meets the required standards.

The auditor considers many factors in determining the nature, timing, and extent of auditing procedures to be performed in an audit of an entity's financial statements. One of the factors is the existence of an internal audit function. This section provides the auditor with guidance on considering the work of internal auditors and on using internal auditors to provide direct assistance to the auditor in an audit performed in accordance with generally accepted auditing standards (AICPA, 1991).

An automated and systematic forensic model for a preventive audit can well support an external audit. A systematic and disciplined approach of internal audit work will encourage external auditors to rely on internal audit work (Wood, 2004). External auditors can reduce time and resources for an audit, and obtain information from an inside view of internal auditors.

An established discriminant function in a forensic model could be used, if desired, in a preventive capacity to block questionable activity. This mechanism is similar to a control system, but associated with an audit process and therefore considered a meta-control. A well-designed internal control system with this meta-control structure could detect and prevent anomalies and/or fraud on a timely basis, and allow management to correct problems prior to execution. Also, management could use preventive mechanisms in continuous monitoring to monitor and manage key controls. In general, the three types of predictions (risks, control trends, and levels and flows) can be used complementarily.

\footnotetext{
${ }^{2}$ The Auditor's Consideration of the Internal Audit Function in an Audit of Financial Statements
} 


\section{METHODOLOGICAL ISSUES}

As discussed earlier, most accounting and auditing standards were set prior to the existence of current information technologies. Bringing the audit close to the event and on a frequent basis, and automating many of its processes raises a series of methodological questions that will eventually affect the economics, practice, and standards of auditing.

\section{Quality of prediction}

Organizations and processes vary widely in data consistency and the distributional nature of data. Factors such as cyclicality, periodicity, nature of the product, and other items have a significant impact on the usefulness of associated predictions. There is no sufficient empirical evidence to support creation of a contingency model that would provide specific guidance concerning what models should be implemented, as well as where and how these models should be used. Initial intuition indicates that, if historical processes are better predictable, they would be better suited for use in model development.

\section{Auditor independence}

Earlier in this paper, a preventive audit was described that "transactions are potentially not executed if found to have a high threshold of risk in the preventive mode and submitted to a special audit review group that subsequently deals with the transactions. This places auditors in an operational mode and raises questions of independence from the traditional point of view." The traditional audit required that, due to the manual intensity of processes, auditors be very independent on a formal basis. This was limited by the fact that auditees paid the external auditor and internal auditors reported to financial management. Moving forward, as systems become more automated and audit processes have to be inbuilt and automatic, an exception review function becomes important. This review function needs to be defined formally and maintain a large degree of objectivity, but not necessarily a strictly defined state of independence.

\section{Materiality}

Materiality is a concept of acceptable relative error in transactions. The fuzzy definition of materiality in audit standards basically represents a tradeoff of the 
benefits of review and costs of manually performing such an examination. With modern automation and full population testing, the tradeoffs focus more on the benefits of data quality and the costs of meta-review. In this new setting, likely relative error thresholds will be contingent on actual corporate circumstances, the type of predictive model being used, and the cost of review of data in the "audit by exception" approach (Vasarhelyi and Halper, 1991).

\section{Level of scrutiny}

The economics of audit review has been changed by automation, thus affecting materiality. Consequently, rather than relying on a generic audit standard, the level of scrutiny of business transactions is probably more related to business needs of the auditee. This scrutiny will depend on the power of analytical procedures and the economic value to the corporation relative to the degree of scrutiny. For instance, as analytic processes become more automated, these capabilities will eventually become integral components of packaged software such as ERPs and audit tools. In these systems, after the costs of acquisitions, the variable cost will be minimal but the cost of human selection and review will be substantial (Issa, 2013). Thus, auditors will have to be cognizant of this in deciding the level of scrutiny that suits a company's needs.

\section{Timing}

Vasarhelyi et al. (2010a) discuss the timing of the continuous audit "Even more importantly, the word 'continuous' undoubtedly would not be used today, because it implies a frequency of auditing that is both difficult to achieve technically without impacting the operations of the entity's IT systems, and probably beyond the needs of most users. The different elements of a corporate information system have different pulses and natural rhythms. The assurance process must be coherent with these rhythms to be useful and effective." The CICA/AICPA (1999) illustrate a continuous audit example with an "evergreen opinion" that is always unqualified until an exception occurs that changes its nature. Such an exception now must be generated by predictive analytic procedures, weighted a-priori, and qualified for human review.

\section{Nature of procedures}

Organizations and processes vary widely, and this affects the way auditors can investigate and analyze each procedure. Analytical methods in auditing range 
from basic financial ratios (Kinney, 1987) to more complicated methods such as statistical analysis (Kinney and Salamon, 1982; Wilson and Hudson, 1989, Chen and Leith, 1999) and data mining techniques (Kogan et al., 2010). Auditors have to understand a target process that they want to review, and carefully select analytical methods and relevant variables that are most suitable for that process. The predictive audit could readily utilize data mining and machine learning techniques that are able to predict the outcome of a future observation (Tan et al., 2005). To determine an algorithm to be used, data type must be taken into consideration. If information about the classification of an outcome (e.g. fraud or not fraud) is available, a supervised learning algorithm can be used. Conversely, if class label information is not obtainable, an unsupervised learning algorithm is appropriate.

\section{EXAMPLE OF A POTENTIAL PREDICTIVE AUDIT MODEL IMPLEMENTATION}

Practically speaking, creating a model for predictive audit requires a minimal baseline number of transactions to create a profile for each activity such as sale cancellations and fraud detection. A prediction model is an adaptive model that will learn behavior from objects of interest and predict outcomes. Thus, the data set should be of sufficient size, and representative of the population so that the model will have predictive power. Prediction results are used to periodically fine tune and update the prediction model. The predictive audit can be used in many other areas, and could help solve business problems as well as obtain competitive advantages. For example, a company could better identify risk areas in the risk assessment process. In addition, the predictive audit could be used to classify specific customer profiles that are of interest. As another example, a bank could predict customers that have a high probability of defaulting on loans or engaging in credit card fraud. Also, an insurance company could identify customers that have a high probability of filing claims. Finally, a government or an IT department could predict security breaches (SAS, 2012).

The application of the predictive audit is illustrated in a study by Kuenkaikaew and Vasarhelyi (2013). Specifically, they applied the predictive audit to 607,189 records of sale transactions over a six month period to discover whether each 
transaction would be cancelled in the future. Predictive models were created for sales activity in the revenue cycle, which was considered as a high risk business process. The bank in this study has a special type of savings account that a customer must have open for a predefined period before he/she can withdraw money. However, if a customer is not satisfied with the product, he/she can ultimately get his/her money back. In the revenue process, sales employees were compensated according to the total points that they accrue from sales transactions with customers.

Internal auditors were concerned about the validity of sales transactions. In particular, matched transactions occur when sales employees open a savings account that is not legitimate. Often, this situation unfolds when a customer is influenced to open a savings account in order to obtain another service that the client desires. For example, the branch manager might inform the client that, to receive a loan, he/she must first acquire the savings account product, and continues by indicating that this product can be cancelled immediately thereafter at no cost. If these bogus sales transactions are able to be predicted with accuracy, mitigating actions can be performed. Predictive models were created to forecast the status of each sale at the transaction level to determine whether or not that sale transaction will be cancelled in the future. Attributes that were used to create predictive models included past sales information classified by sales employee. This historical information could provide reliable indicators for a future transaction outcome. Specific attributes used in model development included sale cancellation, reimbursement, matched sale, sales to inactive customer, complaint, sales to another employee, and total number of sales transactions.

Several machine learning algorithms were applied to the data set to create predictive models. The algorithms used were decision tree J48 (Smith and Bull, 2003; Youn and McLeod, 2007), logistic regression (Pregibon, 1981; King and Zeng, 2001; Swaminathan and Rogers, 2005), and support vector machine (SVM) (Joachims 1998; Hua and Sun, 2001; Tong and Koller, 2002). All predictive results were compared to determine the most useful model. The results (Table 2) show that SVM outperforms other algorithms and correctly predicts almost 80 percent of the cases, while the accuracy of the decision tree $\mathrm{J} 48$ model and logistic regression model are only 64.23 and 70.16 percent, respectively. 


\begin{tabular}{|l|r|r|r|}
\hline Model/ Measurements (\%) & Accuracy & False positive rate & False negative rate \\
\hline J48 & 64.23 & 35.77 & 48.28 \\
\hline Logistic & 70.16 & 29.84 & 49.70 \\
\hline Support vector machine & 79.36 & 20.64 & 62.80 \\
\hline
\end{tabular}

Table 2: Predictability Evaluation of Predictive Models

(From Kuenkaikaew and Vasarhelyi, 2013)

In addition, each model has different rates relative to false positives and false negatives. Auditors have to consider the trade-offs between costs of investigation and costs that a company may incur due to illegitimate transactions. Internal auditors could select a predictive model that suits their needs based on this cost/benefit analysis, and use the selected model to predict the status of incoming transactions.

\section{CONCLUSIONS}

The traditional audit is retrospective and does not respond to current business needs in a timely manner. An audit is periodically conducted according to audit cycles. Anomalies and frauds, if identified, are often detected long after the associated events. Businesses, for a variety of reasons, still benefit from retroactive audits, but modern analytic and computer technologies have allowed the performance of more than just backward assurance. They can obtain meaningful warning concerning possible errors or irregularities. As such, the nature and timing of an audit should evolve to become more proactive.

Continuous auditing and continuous control monitoring create a contemporary audit that respond well to the real time economy. In order to incorporate a timely response mode within the traditional audit, it must be progressively automated. The three major methods for audit automation and a forward looking audit are characterized as: the progressive audit, the predictive audit, and the preventive audit. Each provides different contributions to $\mathrm{CA} / \mathrm{CM}$ from various perspectives. The progressive audit is a way to initiate audit automation. Audit processes are formalized and automated where possible. Results of the progressive audit can lead to new audit guidelines and a rule book that can be used in subsequent audits. The progressive audit also provides a good foundation for future instantiation of predictive and/or preventive audits, although these audits require a higher degree 
of automation. Audit and control are usually expensive processes. Companies have to invest substantially in time, funds, and human resources for those processes. The predictive audit can help management and auditors better plan their tasks and facilitate resource allocation. The predictive audit can be applied in a number of business areas to improve performance and maintain competitive advantages.

\section{Further Observations and research needs}

As earlier discussed, organizations, processes, analytic methods, and techniques for treatment of data vary widely. Companies are constantly changing and looking for methods that could give more reliable information. The one solution for all approach (one consolidated financial statement, one audit standard, one opinion) may be replaced by a set of template-based measurements, and, consequently, a set of assurance circumstances and approaches to examination. Most likely, the basically bimodal opinion will give way to some form of rating per segment, per account, per process, and relative to the disclosure (probably disguised) of the nature of anomalies found in risks, controls, and levels and flows.

External and internal auditors have to carefully scrutinize the implementation of the predictive and preventive audits. Even though the predictive audit is named as an audit, it can be applied to both CA and CM. As mentioned earlier, CA and CM techniques are interchangeable/ complementary where appropriate. Evolving to a predictive audit methodology raises a series of methodological questions that must be addressed. They involve quality of prediction, auditor independence, level of scrutiny, materiality, timing, the nature of procedures, and many other issues.

The predictive audit is a new way of auditing, and could create substantive changes an auditing. Also, some of the key extant research raises certain questions: 1) What is the level of scrutiny auditors could employ to maintain an acceptable degree of objectivity? 2) How can the three levels of controls in business (risks, control trends, and levels and flows) be predicted? 3) What is the recommended model or methodology for prediction? Furthermore, research on methodological design and implementation of the predictive audit are needed. This research might entail qualitative surveys of auditing firms as well as studies of emerging practices in the insurance and banking industries. Future research in 
these areas will provide additional insight and better clarify the path to deployment of the predictive audit.

\section{ACKNOWLEDGEMENTS}

We are grateful for comments received from Paul Byrnes, and two anonymous reviewers.

\section{REFERENCES}

AHMED, M. M.; N. DHAFR. (2002): "Establishing and improving manufacturing performance measures", Robotics and Computer-Integrated Manufacturing vol. 18, n. 3:171-176. http://dx.doi.org/10.1016/S07365845(02)00 $\underline{007-8}$

ALFURAIH, S. I., N. T. SUI; D. MCLEOD. (2002): "Using trusted email to prevent credit card frauds in multimedia products", World Wide Web vol. 5 n. 3:245-256. http://dx.doi.org/10.1023/A:1020940830716

ALLES, M. G., G. BRENNAN, A. KOGAN; VASARHELYI, M. A. (2006): "Continuous monitoring of business process controls: A pilot implementation of a continuous auditing system at Siemens". International Journal of Accounting Information Systems vol. 7 n. 2:137-161. http://dx.doi.org/10.1016/j.accinf.2005.1 $\underline{0.004}$

ALLES, M. G.; KOGAN, A.; VASARHELYI, M. A. (2013): "Principles and Problems of Audit Automation", Working paper. Rutgers Business School.

AMERICAN INSTITUTE OF CERTIFIED PUBLIC ACCOUNTANTS (AICPA). (1991): "Statement on Auditing Standards No. 65: The Auditor's Consideration of the Internal Audit Function in an Audit of Financial Statements". New York: AICPA.

ASHBAUGH-SKAIFE, H.; COLLINS, D. W.; KINNEY, W. R.; LAFOND, R. (2009): "The Effect of SOX Internal Control Deficiencies on Firm Risk and Cost of Equity", Journal of Accounting Research vol. 47 n. 1:1-43. http://dx.doi.org/1 0.1111/j.1475-679X.2008.00315.X 
BROWN, C. E.; WONG, J. A.; BALDWIN, A. A. (2007): "Research Streams in Continuous Audit: A Review and Analysis of the Existing Literature", Journal of Emerging Technology in Accounting vol. 4 n. 1:1-28. http://dx.doi.org/10.2308/jet a.2007.4.1.1

CHAN, D. Y.; VASARHELYI, M. A. (2011): "Innovation and practice of continuous auditing". International Journal of Accounting Information Systems vol. 12 n. 2:152-160. http://dx.doi.org/10.1016/j.accinf.2011.01.001

CHEN, Y.; LEITCH, R. A. (1999): "An Analysis of the Relative Power Characteristics of Analytical Procedures", Auditing: A Journal of Practice \& Theory vol. 18 n. 2:35-69. http://dx.doi.org/10.2308/aud.1999.18.2.35

CHURCH, B. K.; MCMILLAN, J. J.; SCHNEIDER, A. (2001): "Factors affecting internal auditors' consideration of fraudulent financial reporting during analytical procedures", Auditing: A Journal of Practice \& Theory vol. 20 n. 1:65-80. http://dx.doi.org/10.2308/aud.2001.20.1.65

CICA/AICPA. 1999. "Continuous Auditing Research Report”. Toronto, Canada: The Canadian Institute of Chartered Accountants.

COHEN, J. R., KRISHNAMOORTHY, G.; WRIGHT, A. M. (2000): "Evidence on the Effect of Financial and Nonfinancial Trends on Analytical Review". Auditing: A Journal of Practice \& Theory 19 (1):27-48. http://dx.doi.org/10.2308/ aud.2000.19.1.27

CORNISH, D. B.; CLARKE, R. V. (2003): “Opportunities, precipitators and criminal decisions: A reply to Wortley's critique of situational crime prevention”. Crime prevention studies, vol. 16:41-96.

DEBRECENY, R. S. (2006): "Re-engineering IT Internal Controls: Applying Capability Maturity Models to the Evaluation of IT Controls". System Sciences, 2006. HICSS'06. Proceedings of the 39th Annual Hawaii International Conference.

DEL-REY-CHAMORRO, F. M.; ROY R.; WEGEN, B. V. ; STEELE, A. (2003): "A framework to create key performance indicators for knowledge management solutions". Journal of Knowledge Management vol. 7, n. 2:46-62. http://dx.doi.org $\underline{\text { /10.1108/13673270310477289 }}$ 
DOYLE, J. T., GE, W.; MCVAY, S. (2007): “Accruals Quality and Internal Control over Financial Reporting”. The Accounting Review vol. 82 n. 5:11411170. http://dx.doi.org/10.2308/accr.2007.82.5.1141

ECONOMIST. (2002): “The real time economy”. 31 January.

ELDER-DE-AQUINO, C., MIYAKI, E.; SIGOLO, N.; VASARHELYI, M. A. (2013): "Increasing Audit Efficiency through Continuous branch KPI Monitoring”. Working paper.

GLOVER, S. M., PRAWITT, D.; ROMNEY, M. B. (2000): "The software scene", Internal Auditor vol. 57 n. 4:49-57.

GREEN, W. J.; TROTMAN, K. T. (2003): “An examination of different performance outcomes in an analytical procedures task", Auditing: A Journal of Practice \& Theory vol. 22 n. 2:219-235. http://dx.doi.org/10.2308/aud.2003.22.2. $\underline{219}$

HIRST, D.; KOONCE, L. (1996): “Audit Analytical Procedures: A Field Investigation". Contemporary Accounting Research vol. 13, n. 2:457-486. http://dx.doi.org/10.1111/j.1911-3846.1996.tb00511.x

HUA, S.; SUN, Z. (2001): "Support vector machine approach for protein subcellular localization prediction”, Bioinformatics vol. 17 n. 8)721-728. http://dx.doi.org/10.1093/bioinformatics/17.8.721

ISSA, H. (2013). "Exceptional Exceptions". Dissertation in progress. Rutgers Business School.

JOACHIMS, T. (1998): "Text categorization with support vector machines: Learning with many relevant features", Machine learning: ECML-98:137-142. http://dx.doi.org/10.1007/BFb0026683

KAPLAN, R. S.; NORTON, D. P. (1992): “The balanced scorecard-measures that drive performance", Harvard business review vol. 70 n. 1:71-79. PMid:10119714 KIM, Y. (2011): “Continuous Monitoring: Macro- and Micro-level Control". Unpublished PhD. Dissertation, Rutgers Business School. 
KING, G.; ZENG, L. (2001): "Logistic regression in rare events data", Political analysis vol.9 n. 2:137-163. http://dx.doi.org/10.1093/oxfordjournals.pan.a004868 KINNEY, W. R. (1987): “Attention-directing analytical review using accounting ratios: A case study". Auditing: A Journal of Practice \& Theory vol. 6 n.2:59-73.

KINNEY, W. R.; SALAMON, G. L. (1982): "Regression analysis in auditing: A comparison of alternative investigation rules", Journal of Accounting Research, vol. 20 n. 2:350-366. http://dx.doi.org/10.2307/2490745

KOGAN, A., ALlES, M. G.; VASARHELYI, M. A. WU, J. (2010): “Analytical Procedures for Continuous Data Level Auditing: Continuity Equations". Working paper.

KPMG. (2010): “What is Driving Continuous Auditing/Continuous Monitoring Today?” White paper KPMG LLP.

KUENKAIKAEW, S.; VASARHELYI, M. A. (2013): "Predictive Audit: transactions status prediction”. Working paper. Rutgers Business School.

LI, P., CHAN, D. Y.; KOGAN, A. (2013): “Continuous Auditing: Exception Prioritization Framework \& Experiment". Working paper. Rutgers Business School.

LitTley, J. R.; COSTEllo, A. M. (2009): “CA/CM As Preventive Care Against Fraud". White paper KPMG LLP.

MOON, D. (2013): "Continuous Risk Monitoring and Dynamic Audit Planning Using KRIs”. Working paper. Rutgers Business School.

O'DONNELL, E.; SCHULTZ, J. J. (2003): “The influence of business-processfocused audit support software on analytical procedures judgments", Auditing: A Journal of Practice \& Theory vol. 22, n. 2:265-279. http://dx.doi.org/10.2308/aud. 2003.22.2.265

PREGIBON, D. (1981): "Logistic regression diagnostics". The Annals of Statistics: 705-724. http://dx.doi.org/10.1214/aos/1176345513

PRICEWATERHOUSECOOPERS (2006): "State of the internal audit profession study: Continuous auditing gains momentum”. PricewaterhouseCoopers.

SAS. (2012): "Drive Your Business with Predictive Analytics". White paper. 
SISALEM, D.; KUTHAN, J.; EHLERT, S. (2006): "Denial of service attacks targeting a SIP VoIP infrastructure: attack scenarios and prevention mechanisms", Network, IEEE vol. 20 n.5:26-31. http://dx.doi.org/10.1109/MNET.2006.1705880

SMITH, M.; BULL, L. (2003): "Feature construction and selection using genetic programming and a genetic algorithm", Genetic Programming: 93-100.

SWAMINATHAN, H.; ROGERS, H. J. (2005): "Detecting differential item functioning using logistic regression procedures", Journal of Educational measurement, vol. 27 n.4:361-370. http://dx.doi.org/10.1111/j.1745-3984.1990.tb 00754.x

TABOR, R. H.; WILLIS, J. T. (1985): "Empirical evidence on the changing role of analytical review procedures", Auditing: A Journal of Practice and theory, vol. 4 n. 2:93-109.

TAN, P.-N., STEINBACH, M.; KUMAR, V. (2005): "Introduction to data mining". Boston: Pearson Addison Wesley.

TEETER, R. A. (2013). "Three Essays on the Enhanced Audit". Working paper. Rutgers Business School.

TEETER, R. A.; BRENNAN, G. (2010): "Aiding the audit: using the IT audit as a springboard for continuous controls monitoring". Available at SSRN 1668743.

TEETER, R. A.; VASARHELYI, M. A.; ALLES, M. G. (2010): "Remote Audit: A Research Framework". Working paper. Rutgers Business School.

TONG, S.; KOLLER, D. (2002): "Support vector machine active learning with applications to text classification", The Journal of Machine Learning Research, vol. 2:45-66.

VASARHELYI, M. A. (2012): "Financial Accounting Standards Should Not Matter: It's Just a Layer", Journal of Information Systems vol. 2, n. 26.

VASARHELYI, M. A.; ALLES, M. G. (2005): “Continuous Monitoring and Assurance in a Real Time Economy. The Impact of European Integration On the National Economy", Business Information Systems Babes-Bolyai University of Cluj-Napoca:1-20. 
VASARHELYI, M. A.; ALLES, M. G.; KOGAN, A. (2004): "Principles of analytic monitoring for continuous assurance", Journal of Emerging Technologies in Accounting, vol. 1:1-21. http://dx.doi.org/10.2308/jeta.2004.1.1.1

VASARHELYI, M. A.; ALLES, M. G.; KUENKAIKAEW, S.; LITTLEY J. (2012a): "The Acceptance and Adoption of Continuous Auditing by Internal Auditors: A Micro Analysis", International Journal of Accounting Information Systems, vol. 13:267-281. http://dx.doi.org/10.1016/j.accinf.2012.06.011

VASARHELYI, M. A.; ALLES, M. G.; WILLIAMS, K. T. (2010a): “Continuous Assurance for the Now Economy". A Thought Leadership Paper for the Institute of Chartered Accountants in Australia.

VASARHELYI, M. A.; GREENSTEIN, M.. (2003): "Underlying Principles of the Electronization of Business: A Research Agenda", International Journal of Accounting Information Systems, vol.4 n.1:1-25. http://dx.doi.org/10.1016/S1467$\underline{0895(03) 00002-2}$

VASARHELYI, M. A.; HALPER, F. B. (1991): "The continuous audit of online systems", Auditing: A Journal of Practice \& Theory, vol. 10 n.1:110-125.

VASARHELYI, M. A.; ROMERO, S.; KUENKAIKAEW, S.; LITTLEY, J. (2012b): "Adopting Continuous Auditing/Continuous Monitoring in Internal Audit", ISACA Journal 3.

VASARHELYI, M. A.; TEETER, R. A.; KRAHEL, J. P. (2010b): "Audit education and the real-time economy", Issues in Accounting Education, vol. 25, n.3:405-423. http://dx.doi.org/10.2308/iace.2010.25.3.405

VASARHELYI, M. A. (2011). "The Coming Age of Continuous Assurance". Insight: Melbourne Business and Economics, vol. 9:23-30.

VASARHELYI, M. A., KOGAN, A. (1999), "Continuous auditing and IT developments", IS Audit and Control Journal, vol. 5:17-18.

VENKATRAMAN, N.; RAMANUJAM, V. (1986): "Measurement of Business Performance in Strategy Research: A Comparison of Approaches", The Academy of Management Review, vol. 11, n. 4:801-814. http://dx.doi.org/10.2307/258398

VERVER, J. (2012): "Why You Need Internal Audit at the Table". Published on Business Finance (http://businessfinancemag.com). 
WARREN, J. D.; TEETER, R. A.; AL-AWADHI, A. (2012): “Order-to-Cash Reengineering”. Working paper. Rutgers Business School.

WILSON, A. C.; HUDSON, D. (1989): “An empirical study of regression analysis as an analytical procedure", Contemporary Accounting Research, vol. 6, n.1:196-215. http://dx.doi.org/10.1111/j.1911-3846.1989.tb00753.x

WOOD, D. A. (2004): “Increasing value through internal and external auditor coordination". Prepared for the IIA Research Foundation.

YOUN, S.; MCLEOD, D. (2007): “A comparative study for email classification. Advances and Innovations in Systems", Computing Sciences and Software Engineering, 387-391. 